\begin{tabular}{l|c|c|c|c|} 
DOI: http://dx.doi.org/10.54085/ap.covid19.2021.10.2.5 \\
Annals of Phytomedicine: An International Journal \\
http://www.ukaazpublications.com/publications/index.php \\
Print ISSN : 2278-9839 Online ISSN : 2393-9885
\end{tabular}

\title{
Agents of mucormycosis outbreak associated with COVID-19
}

\author{
Shadma Wahab*, Khursheed Muzammil*, Nazim Nasir**, Atiq ul Hasan**, Zeba Siddiqui***, Pradeep Aggarwal**** and \\ Sumbul Nasir***** \\ Department of Pharmacognosy, College of Pharmacy, King Khalid University, Abha-61421, Saudi Arabia, KSA \\ * Department of Public Health, College of Applied Medical Sciences, Khamis Mushayt Campus, King Khalid University, Abha-61421, Saudi \\ Arabia, KSA \\ ** Department of Basic Medical Sciences, College of Applied Medical Sciences, Khamis Mushait Campus, King Khalid University, Abha- \\ 61421, Saudi Arabia, KSA \\ *** Department of Basic Medical Sciences, College of Applied Medical Sciences, Mahala Campus, King Khalid University, Abha-61421, \\ Saudi Arabia, KSA \\ ****Department of Community and Family Medicine, All India Institute of Medical Sciences, Rishikesh-249203, Uttarakhand, India \\ ***** CHC Munda Pandey-244504, Moradabad, Uttar Pradesh, India.
}

\section{Article Info}

Article history

Received 25 July 2021

Revised 12 September 2021

Accepted 13 September 2021

Published Online 30 December 2021

\section{Keywords}

Pulmonary infections

Fungal infection

Invasive fungal disease

Post-COVID-19

COVID-19

Respiratory infections

SARS

\begin{abstract}
Mucormycosis is a life-threatening infection. Mucormycetes causes a wide range of diseases, including pneumonia, rhinosinusitis, internal organ spread, gastrointestinal tract involvement, and skin and soft tissue infection. It infects predominantly with hematological malignancies, transplantation, immunocompromised, and diabetes mellitus patients. The most severe type of the disease is a disseminated disease, which is linked to significant immunosuppression. Currently, this disease is more prevalent in the COVID19 pandemic because of erroneous steroid use and untreated diabetes. However, there is a scarcity of study and information on the COVID-19 and mucormycosis connection. According to the latest research, mucormycosis cases are rising in developed and developing nations, and only a few therapies are available. The exact burden of mucormycosis is unclear; however, it is likely to be greater than recorded instances due to mucormycosis epidemiological changes. As a result of the delay in identifying this severe illness, appropriate antifungal medications are delayed, resulting in significant morbidity and death. A few drugs are underclinical trials for their efficacy. Other obstacles to treat patients are lack of reliable diagnostic non-invasive tests. This review article draws the attention of its readers and clinicians towards the agents of mucormycosis and discuss the various cases to manage this fungal infection.
\end{abstract}

\section{Introduction}

The SARS-CoV-2 (severe acute respiratory syndrome coronavirus2) has been related to many opportunistic fungal and bacterial infections (Kubin et al., 2021; Ahmad et al., 2021). Pathogens that are developing or re-emerging, pose a worldwide threat to public health (Gao, 2018). Fungal pathogens Candida and Aspergillosis have been reported to be accountable for co-infection in people with COVID-19 (Paltauf, 2021). Coronaviruses are enveloped RNA viruses that cause respiratory, hepatic, neurological, and gastrointestinal illnesses in humans, other animals, and birds (Liu, 2014; Weiss and Leibowitz, 2011; Khan et al., 2020). Even though, COVID-19 primarily affects the lungs, several clinical consequences have been observed, including cardiac damage, thromboembolic events, arrhythmia, and immunological dysregulation (Giustino et al., 2020; Tay et al., 2020; Diao et al., 2020; Wahab, et al., 2021). Sufferers with acute respiratory distress syndrome (ARDS) given corticosteroids, broad-spectrum antibiotics, and invasive or noninvasive ventilation are more prone to get co-infections. According

Corresponding author: Dr. Shadma Wahab Department of Pharmacognosy, College of Pharmacy, King Khalid University, Abha-61421, Saudi Arabia.

E-mail: shad.nnp@gmail.com

Tel.: +00966-536039384

Copyright (ㅇ 2021 Ukaaz Publications. All rights reserved.

Email: ukaaz@yahoo.com; Website: www.ukaazpublications.com to a recent report, co-infection is present in $63.64 \%$ of COVID-19 mortality (Lv et al., 2020; Wahab, et al., 2021). Mucormycosis, acknowledged as "black fungus," is a rare but fatal fungal illness found in COVID-19 patients in many Indian states (Singh et al., 2021). Mucormycosis is caused by the mucor mold often found in plants, manure, rotting vegetables, fruits, and soil. These fungi proliferate a vast quantity of spores into the atmosphere. Inhalation is a common way for humans to come into contact with these fungi (Hirabayashi et al., 2019). It affects the sinuses, brain and lungs and may be deadly for immunocompromised or have diabetes or, cancer or people living with HIV/AIDS. Rhino-orbital mucormycosis is becoming more usual in persons with COVID-19. These instances to severe COVID-19 infection and mucormycosis (Singh et al., 2021). Immunocompromised and poorly managed diabetic patients are typically affected, with severe morbidity and death (John et al., 2021). Mucormycosis has also been found in the pulmonary and gastrointestinal tract (Do Monte et al., 2020; Garg et al., 2021).

Until today, few studies have aimed to look for superinfections by fungus, bacteria, or other viruses in SARS-CoV-2 cases (Agrifoglio et al., 2020; Garcia-Vidal et al., 2020). Patients with a mucormycosis (MCR) - like illness, such as rhino-orbital illness and a positive nasal cavity culture, were judged as having "probable" MCR. Individuals with cavitary pneumonia and SARS-CoV-2 infection with mucorales isolated from their respiratory secretions had "putative" MCR. If are very prevalent in India currently. Diabetes mellitus (DM) is linked 
there were signs of infection on arrival, mucormycosis was classed as "concurrent" and "sequential", if a diagnosis was made 72 hours after the COVID-19 diagnosis (John et al., 2021; Bakshi and Kalidoss, 2021). However, research and information concerning the link between COVID-19 and mucormycosis are limited. Early identification and recognition of illness patterns are critical in the treatment of mucormycosis. Patients in low and medium income countries suffered by a lack of access to modern therapies. In the current epidemic situation, it is necessary to sensitize the clinicians as the risk of fatal infection rises. Hence, we reviewed literature reporting mucormycosis in patients to provide updated information.

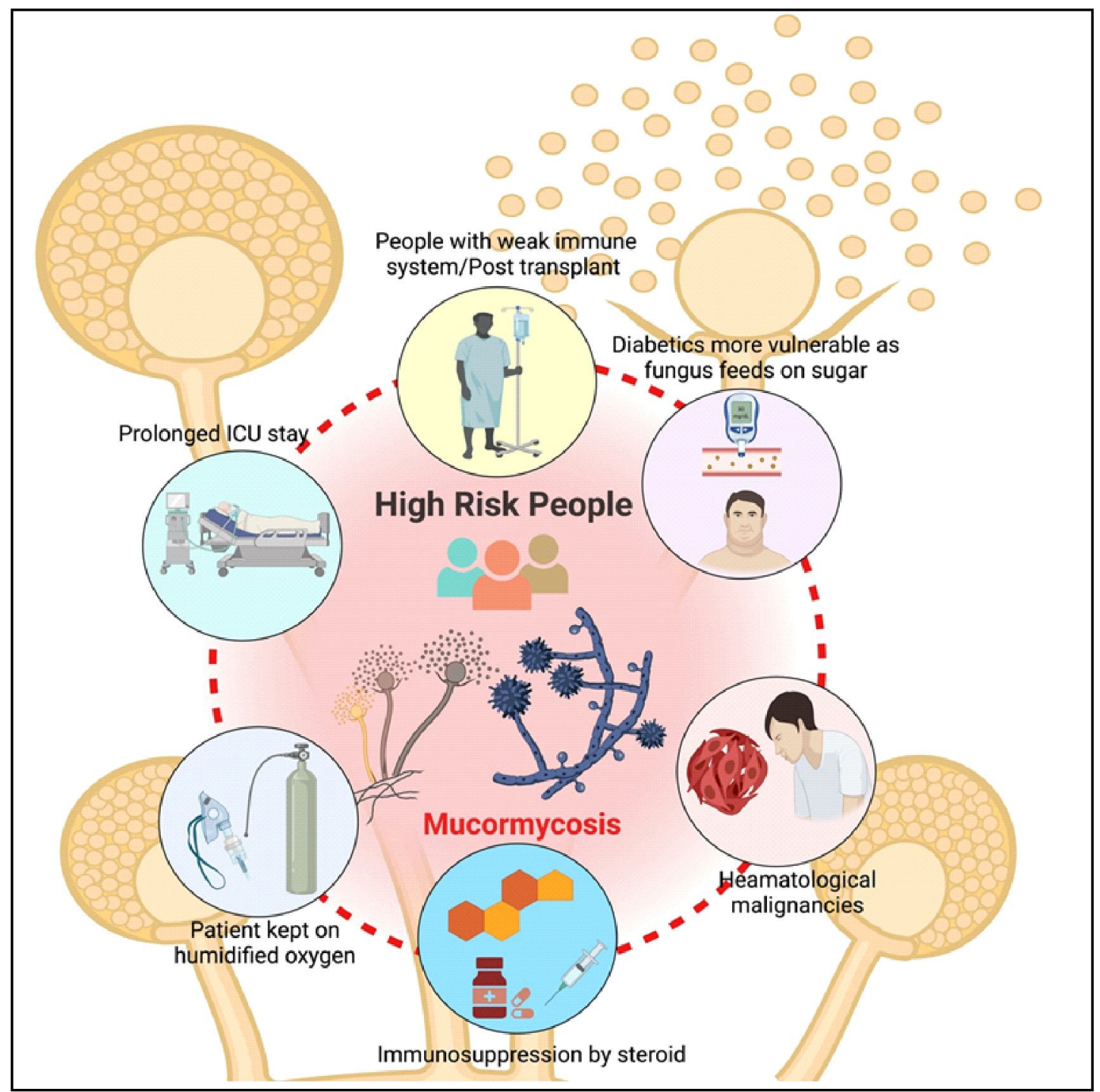

Figure: Graphical abstract.

\section{Mucormycosis types and symptoms}

Mucormycosis is also known as zygomycosis. It is a serious, yet rare fungus caused by mucormycetes, a faction of molds. This fungus may be found throughout the environment. For example, the disease may appear in the lungs or sinuses after breathing spores. This type of mucormycosis is prevalent in those who take medications that lessen the body's potential to fight infections and having severe health issues (Ribes et al., 2000; Petrikkos et al., 2012).

Rhino-cerebral mucormycosis is a sinus infection that can spread to the brain. Mucormycosis of this type is frequent in people with uncontrolled diabetes and kidney transplant recipients (Ahmed et al., 2002; Song et al., 2017). The most common mucormycosis among cancer patients and those receiving stem cell or an organ transplant is pulmonary mucormycosis (Anon 'About Mucormycosis Mucormycosis | CDC', n.d.). Relatively young children are more likely than adults to develop gastrointestinal mucormycosis, low birth weight children, and those treated with antibiotics, surgery, or medications. This is because they have a lower ability to fight sickness and germs (Vallabhaneni and Mody, 2015; Francis et al., 2018). Cutaneous mucormycosis happens when fungus enters the body through a skin breach (for example, after surgery, different types of 
skin trauma or a burn). It is the most prevailing kind of mucormycosis in those who are immune compromised (Anon 'About Mucormycosis | Mucormycosis | CDC', n.d.). Finally, disseminated mucormycosis develops when an infection spreads throughout the body via the bloodstream. In this type of mucormycosis, infection is usually seen in the brain, although it can also damage the spleen, heart, and skin (Anon'About Mucormycosis | Mucormycosis | CDC', n.d.). Mucormycosis types and risk factors have been shown in Figure 1.

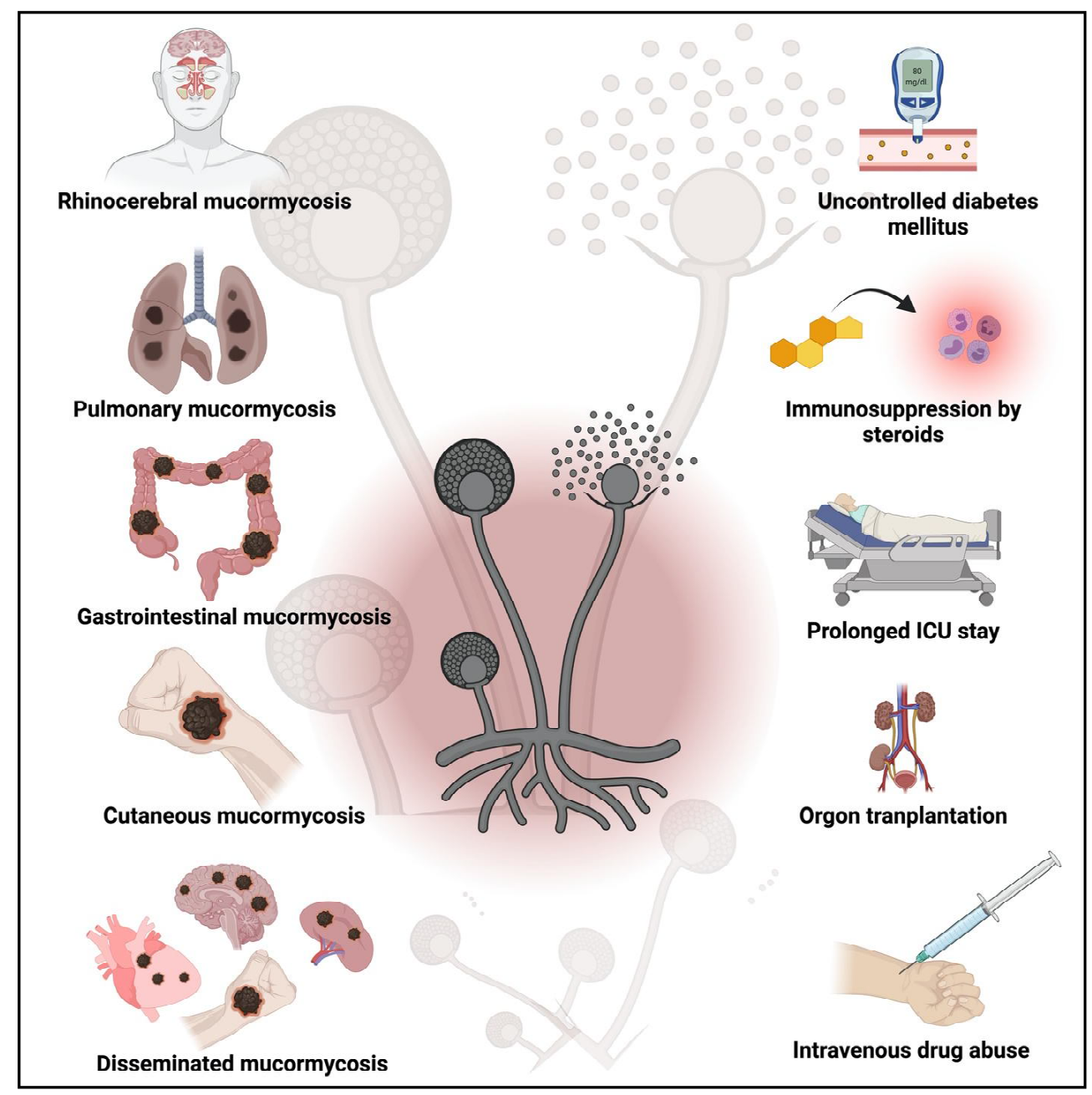

Figure 1: Mucormycosis type and risk factor.

Clinicians should be aware that COVID-19 patients may develop invasive fungal illnesses in the future. Warning symptoms cover redness and pain around the nose or eyes, headache, shortness of breath, coughing, fever, altered mental status, and bloody vomits. In addition, as said by the recommendation, mucormycetes infection would be considered, if there is:

- Pleural effusion, chest pain, worsening of respiratory symptoms.

- Necrosis, thrombosis, skin lesion.

- Blurred or double vision with pain.

- Jaw involvement, loosening of teeth.

- Blackish discoloration of the bridge of nose/palate.

- One-sided facial pain, numbness or swelling, local pain on the cheekbone.
- Nasal discharge (blackish/bloody), congestion or sinusitis-nasal blockade (Anon 'mucormycosis COVID symptoms, treatment: 'Black fungus' infection in COVID-19 patients', n.d.; Ribes $e t$ al., 2000; Petrikkos et al., 2012).

Experts recommend that all cases of a blocked nose in the case of immunosuppression or COVID-19 patients on immunomodulators should not be acknowledged as bacterial sinusitis.

\section{Agents of mucormycosis}

Mucormycosis is a fungal infection spread by the mucorales group of fungi. The gastrointestinal system, soft tissue, skin, bloodstream, rhinocerebral spaces, sinuses, and lungs are potential infection sites (Reiss, 2006; Anaissie et al., 2009). While for a long time, mucormycosis was thought to be an unusual fungal infection that necessitated extensive medical treatment for the elderly (Roden $e t$ al., 2005; Petrikkos et al., 2012; Kontoyiennis et al., 2010; Roilides 
et al., 2009; Lanternier and Lortholary, 2009; Chayakulkeeree et al., 2006). In the current pandemic, the cases of mucormycosis have been rising due to various factors. It demands better management for susceptible people having predisposing conditions such as iron overload, cancer, trauma injury, diabetes and COVID-19 (Garg et al., 2021; Chayakulkeeree et al., 2006). In individuals with hematological malignancies and transplant recipients, mucormycosis is the second most prevalent fungus. Disseminated infection death rates are unacceptably high, with mortality rates exceeding $90 \%$ (Ribes et al., 2000).

\subsection{Uncontrolled diabetes}

Mucormycosis is an invasive fungus that typically impacts uncontrolled diabetics patients (Vijayabala et al., 2013). Diabetes mellitus alters the body's natural immune response to infection in a variety of ways. Hyperglycemia promotes fungal growth while lowering phagocytic and chemotaxis effectiveness, allowing ordinarily harmless species to flourish in acidic conditions. Mucormycosis caused by Rhizopus oryzae is more common in diabetic ketoacidosis patients because these organisms generate the enzyme ketoreductase, which allows them to utilise the patient's ketone bodies (Marx and Stern, 2003). In addition, the capacity of transferrin to bind iron is temporarily disrupted in diabetic ketoacidosis. This mutation disables a critical host defensive mechanism, allowing Rhizopus oryzae to thrive (Artis et al., 1982). The increased vulnerability to Rhizopus oryzae in diabetic mice was studied using diabetic ketoacidosis-induced mice. After being inoculated with $R$. oryzae, all diabetic mice who developed ketoacidosis died within four days.

Furthermore, their blood UIBCs (unbound iron-binding capacity) were considerably lower than normal control mice. This study found that diabetic ketoacidosis causes a reduction in serum UIBC, which promotes $R$. oryzae proliferation in vivo (Abe et al., 1986). Liu and his team wanted to know how iron and glucose affected the expression of such a receptor. They discovered glucose-regulated protein 78 (GRP78), which they think is a new host receptor that allows $R$. oryzae. It is the most common etiologic mucorales species to invade and harm human endothelium cells, but not Aspergillus fumigatus or Candida albicans. Mice with diabetic ketoacidosis (DKA), which are more susceptible to mucormycosis, had shown higher GRP78 expression in their sinuses, lungs, and brains than normal mice. Ultimately, mice with DKA were protected from mucormycosis by GRP78-specific immune serum (Liu et al., 2010). These findings point to a distinct vulnerability to mucormycosis in individuals with DKA, laying the groundwork for developing novel treatment approaches for these fatal diseases. A study comprised 28 patients, 3 hematological malignancy patients, 18 diabetes mellitus patients, and 7 solid organ transplant patients. In 7 solid organ transplant patients, 3 had a rejection episode: three more had cytomegalovirus infection before developing mucormycosis.

It was concluded that mucormycosis treatment requires a multispecialty approach. While the underlying risk factors for the solid organ transplant and diabetes mellitus groups differed, the results were comparable (Al-Obaidi et al., 2021). Martínez-Herrera and his team reviewed seven cases of ROCM associated to diabetes mellitus. Fungal invasion of the vessels progresses speedily because mucormycosis diagnosis necessitates clinical suspicion and prompt intervention. Its diagnosis is a medical emergency. It should preferably include a direct examination for mycological diagnosis and a culture that grows in $24 \mathrm{~h}$. Imaging studies, such as tomography, are also valuable for determining the degree of damage. Surgical debridement allows for the possibility of cure as well as the collection of material for histological confirmation. The most prevalent differential diagnosis is invasive aspergillosis (MartínezHerrera et al., 2021).

A case of a 44-year-old person was published in Lancet. He reported the reduction in vision of his left eye. Ten days before, he was the recipient of intravenous antibiotics, supplemental oxygen, and corticosteroids due to moderate-severe pneumonia due to COVID19. The patient said to the doctors that two days before a blackish patch has developed just below the left eye to the level of his mouth. He had a positive history of diabetes without malignancy. Reports of examinations have shown in the Table 1 and Laboratory investigations described in Table 2.

Table 1: Reports of examinations

\begin{tabular}{|l|l|}
\hline Examinations & Result \\
\hline Temperature & $37^{\circ} \mathrm{C}$ \\
Pulse & 84 beats per min \\
Blood pressure & $118 / 82 \mathrm{~mm} \mathrm{Hg}$ \\
Respiratory rate & 16 breaths per min \\
Pulse oximetry & Oxygen saturation of $96 \%$ on room air \\
Visual acuity & 20/20 in his right eye but no perception of light in his left eye. \\
The patient had in his left eye & Exophthalmos, ophthalmoplegia, and chemosis. \\
\hline
\end{tabular}

Table 2: Laboratory investigations

\begin{tabular}{|l|l|}
\hline Investigations & Result \\
\hline Random blood sugar concentration & $298 \mathrm{mg} / \mathrm{dl}$ (normal 140 or below) \\
Glycated haemoglobin A1c & $9 \cdot 8 \%$ (normal 4-5·6) \\
Arterial blood & $\mathrm{pH} 7 \cdot 4($ normal $7 \cdot 35-7 \cdot 45)$ \\
Serum bicarbonate concentration & $24 \mathrm{mEq} / 1$ (normal 23-30) \\
Mild neutropenia & 1510 neutrophils per $\mu 1$ (normal 1800-6300) \\
\hline
\end{tabular}


The patient received intravenous liposomal amphotericin B at a dose of $5 \mathrm{mg} / \mathrm{kg}$ per day and continued on insulin infusion due to persistent high blood glucose level. Thorough debridement, a left total maxillectomy, and orbital exenteration were done under a general anaesthesia; however, the patient died 6 days later (Chauhan et al., 2021). Diabetes is a global problem that has grown in prevalence rate over the previous decade. It is linked to significant morbidity and impairment, and mortality. Mucormycosis is a fungal infection that affects severely ill patients of any age and any immunosuppression, particularly diabetics.

\subsection{Steroids and their administration to COVID-positive patients}

The rapidly expanding public understanding of SARS-CoV-2 virology opens a plethora of potential therapeutic targets. WHO is continually revising the COVID-19 therapy regimen (Wahab et al., 2020a). Scientists around the globe are looking for therapeutic or defense trials against the virus due to the lack of medicine. It is a concern for clinicians due to the lack of therapeutic alternatives for its treatment of COVID-19. Clinical practice has resorted to last-resort measures based on shaky facts or assumptions to face the COVID-19. In earlier studies, several anti-inflammatory and antiviral therapies, antimalarial medication, and immune-modulating drugs that affect different elements of inflammation were used and addressed (Vellingiri et al., 2020). Doctors say, 'steroids may help patients with severe COVID19 infection. Steroids are medicines that save the lives of severe COVID-19 infection patients. Steroids are sometimes administered for individuals who have tested positive for COVID infection. However, there is some ambiguity and commotion around their use. Usage of corticosteroids in COVID-19 patients is debatable. There is a lack of evidence to prove the connection between corticosteroids and increased survival in MERS-CoV-1 and SARS-CoV-1 patients (Russell et al., 2020; Shang et al., 2020).

Corticosteroids are a group of steroid hormones generated by vertebrates'in adrenal cortex with synthetic analogues. Corticosteroids are divided into two main classes: glucocorticoids and mineralocorticoids. They play a role in stress management, immunological responses, inflammatory control, glucose metabolism, protein catabolism, blood electrolyte levels, and other physiological processes. They also decrease the activity of the immunological system (Auld, 1929). Cortisol, corticosterone, cortisone, dexamethasone, betamethasone, and aldosterone are the most prevalent natural and synthetic corticosteroids. Corticosteroid treatment has a long-term effect, which is especially significant in COVID-19 patients with persistent ground-glass opacities. Therefore, recommended regimen of corticosteroids is more than ten days only for severe cases of COVID-19 (Villar et al., 2020; Wahab et al., 2020b). Another reason to prescribe prolonged therapy in COVID-19 patients with pulmonary fibrosis restrict the post-disease fibrosis. Unfortunately, in COVID-19, long-term corticosteroid therapy might unexpectedly result in poor therapeutic results (Mishra and Mulani, 2021). Prolonged corticosteroid treatment may result in what is known as the prolonged COVID syndrome, including tiredness and psychological problems caused by adverse medication relation steroid responses such as psychiatric symptoms, neuromuscular weakness and myopathy (Warrington and Bostwick, 2006; KP et al., 2006).

Misuse of steroids is a precipitating behind black fungus cases. Indiscriminate use of steroids has led to the surge in black fungus cases in India. Treatment has several noticeable adverse effects. It is an important question to raise, what are the indications to administer steroids in COVID patients? Steroids are, in a nutshell, lifesaving. There is sufficient evidence of their efficacy in critical COVID patients who require oxygen, BiPAP, or ventilation who suffer respiratory distress. The viral replication phase is the first week of COVID. Fever, body pain, headache and cold are initial symptoms when steroids should not be administered. Patients have a high fever and self-medicate with steroids or pressurize their doctors to prescribe them. Steroids will temporarily mask the fever symptoms might sort of settle; it might give a sense of false security that patients are getting better. However, in three-five days, patients have a very high fever, cough, respiratory involvement. Results have shown in various cases that many patients who initially took steroids end up with bad pneumonia. The indication for steroids in COVID-19 is in the second week when patients have respiratory distress. Hence, the need for oxygen is high, and the oxygen saturation level is less than 93. At this stage, inflammatory markers in the blood are high, D-dimer, CRP, procalcitonin; all these parameters need to be checked, the ferritin levels also examine simultaneously, and CT scan shows moderate to severe pneumonia.

A study was conducted in Egypt in which researchers observed the same phenomenon of COVID-19 associated mucormycosis (CAM). From March $15^{\text {th }}$ to May $15^{\text {th }}, 2021$, all patients with imaging signs of bone damage and suspected fungal sinusitis after verified COVID19 evaluation by researchers were included. Regardless of the clinical stage of COVID-19, all patients got corticosteroid treatment due to social media promotion of high-dose steroids (Alfishawy et al., 2021). Experts agree that steroids are a powerful weapon. Still, they must be used cautiously at the right time, dose, and duration in moderate to severe cases, to prevent secondary infections such as the 'black fungus' caused by prolong use of steroids in COVID-19.

\subsection{Prolonged ICU stays}

Intensive care unit (ICU) treatment is required for about $5 \%$ of patients with COVID-19 (Wu and McGoogan, 2020). Secondary infections, such as invasive pulmonary aspergillosis (IPA), are a significant concern for these individuals (Lescure et al., 2020). COVID-19 patients who were mechanically ventilated found suspected IPA in almost one-third of cases, a frequency equivalent to that seen in influenza patients (Schauwvlieghe et al., 2018; J et al., 2012; Alanio et al., 2020). Complex surgical and medical issues, numerous invasive operations, extended antibiotic therapy are the leading factors to the rise in fungal infections in ICU (Darouiche, 2009; Blot et al., 2008). Hospitalization and ambulatory care are established risk factors for bacteria, yeasts, and Aspergillus species infection. Patients with mucormycosis spend a substantial period in intensive care units, and mortality remains high despite advancements in diagnosis and therapy (Bassetti and Bouza, 2017). Candidaemia is the most common fungal infection. According to the EPIC II research, fungi accounted for $19 \%$ of infections identified in ICU patients, including 1,265 ICUs from 75 countries (Vincent et al., 2009). The increasing incidence of mucormycosis with hematological malignancies are due to susceptibility to antifungal agents and high invasive power. A study was conducted to evaluate the epidemiology of mucormycosis in ICU. In between 2008 and 2017, a retrospective multi-centre study was conducted in 16 French ICUs. It was a comparative study in ICU patient's survival. This study was not able to know the factors 
associated with ICU survival. This research lacked the overall prognosis of mucormycosis in ICU in hematological malignancies patients (Claustre et al., 2020).

Zygomycetes, Aspergillus species, Scedosporium and Fusarium species are rare harmful fungi developed in recent decades. For a positive outcome, timely diagnosis and appropriate treatment are critical. Several laboratory procedures have been developed with blood cultures in the expectation of identifying the disease earlier. The antifungal arsenal has also been increased, providing treatment options suited to the needs of individual patients (Paramythiotou et al., 2014). Therefore, there is a need to identify successive serum samples in galactomannan and Aspergillus in lower respiratory secretions in COVID-19 ICU patients. Consultants can choose from the newer azoles, old polyene class, echinocandins and newer azoles. For the proper antifungal drug choice, consider factors such as the patient's clinical state and current co-morbidities, local epidemiology data, and the treatment goal. To identify the best antifungal treatment and drug, there is a need to examine the factors such as local epidemiology data, the patient's clinical state, the treatment goal, and current co-morbidities.

\subsection{Co-morbidities-post transplant/malignancy}

Mucormycosis is a fatal fungal infection that has become increasingly prevalent in recent years. Mucormycosis is now a potential problem for transplant patients, representing $2 \%$ and $8 \%$ of invasive fungal infections, respectively, in recent cohorts of allogeneic stem-cell and solid-organ transplant recipients. Mucormycosis is most common after transplantation, occurring $>3$ months afterwards. However, cases have been recorded previously, notably among graft-transmitted infection and liver transplant patients (Fanny Lanternier et al., 2012).
Hematopoietic stem-cell transplant and solid-organ transplant recipients may find substantial death rates (Petrikkos et al., n.d.; Skiada et al., 2011; Lanternier et al., 2012). The increased risk of invasive fungal infection in transplant recipients is due to the antibodies used for immunosuppression and powerful T cell-depleting medications (Chamilos et al., 2008). Lungs are the most common infection site in solid organ transplant patients. Prompt diagnosis is complex and has an impact on the result. Surgical and medicinal treatments are used to treat the condition. However, various medicines have been employed in the treatment of mucormycosis. Newer agents have a lot of potentials. Amphotericin B remains the gold standard for mucormycosis treatment (Fanny Lanternier et al., 2012). Most research on mucormycosis in transplant recipients has been retrospective and descriptive, and many have been conducted at a single hospital. Furthermore, the scarcity of current autopsy statistics from transplant patients makes it difficult to accurately assess mucormycosis epidemiological patterns in this population (Hamdi et al., 2014). A probable environment of fungal infection in high-risk peoples have been represented in Figure 2.

One of the most prevalent reason of death after transplantation is post-transplant malignancy, which has controllable and nonmodifiable risk factors. However, the current pharmacological arsenal and future immunologic monitoring capabilities hold the promise of customizing post-transplant treatment to lessen the uncertainty of post-transplant malignancy without sacrificing graft survival to maximize transplant results. An interim guideline was released by the World Health Organization (WHO) in September 2020 to use steroids such as dexamethasone and corticosteroids to treat the patients of COVID-19.

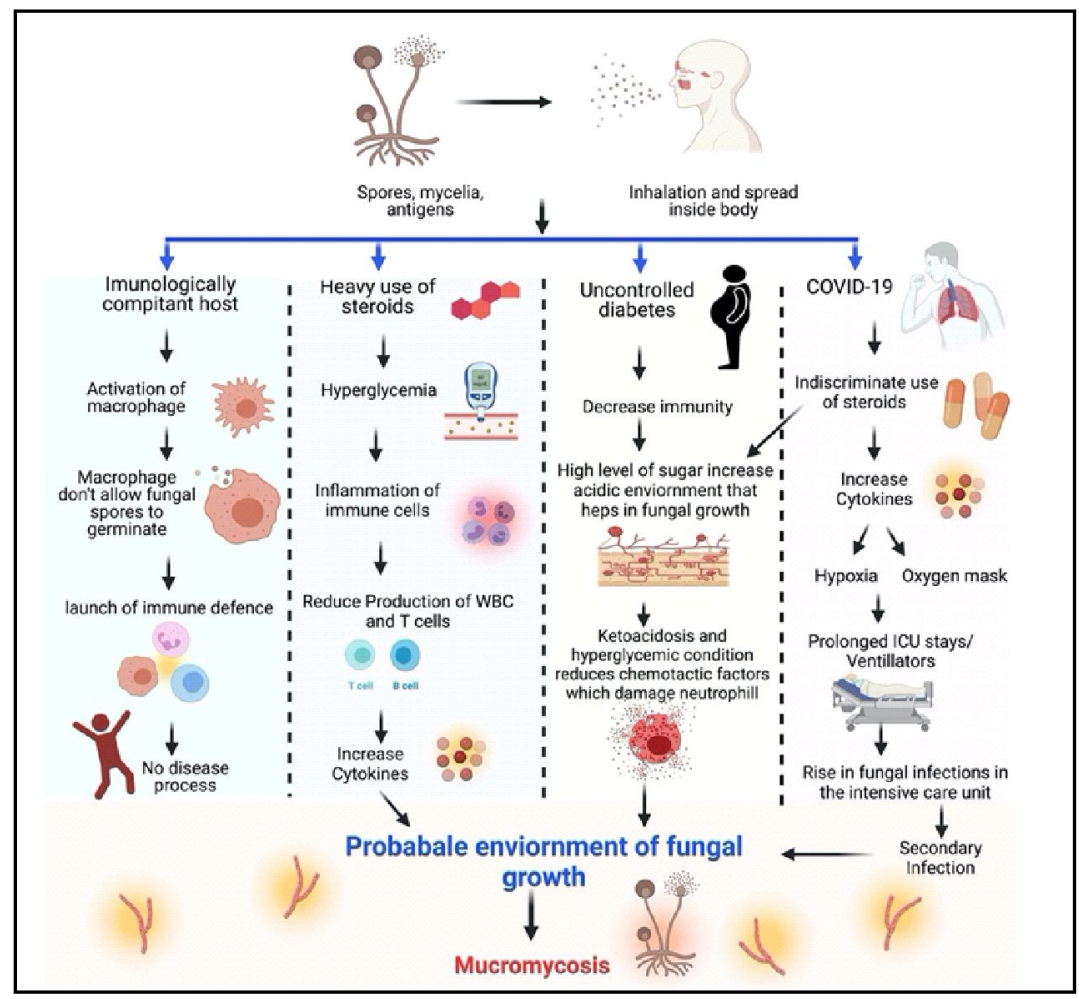

Figure 2: Probable environment of fungal infection in high-risk peoples. 
It made two recommendations. According to the WHO, the first recommendation is corticosteroids should be administered intravenously or orally to patients with severe COVID-19. The second recommendation of WHO suggested that corticosteroids should not be used in non-severe cases of COVID-19 unless the patient is previously taking for another disease.

- The medicine can be administered once a day for 7-10 days.

- $6 \mathrm{mg}$ dexamethasone, equal to $160 \mathrm{mg}$ hydrocortisone $(50 \mathrm{mg}$ every 8 hours or $100 \mathrm{mg}$ every 12 hours), $40 \mathrm{mg}$ prednisone, and $32 \mathrm{mg}$ methylprednisolone should be taken every day $(8 \mathrm{mg}$ every 6 hours) (Annane, 2021; Anon'• According to the WHO, corticosteroids should be administered intravenously or orally to patients with severe COVID-19. - Google Search', n.d.).

According to the research, although steroids are beneficial in reducing infection linked with inflammation, they "should be administered responsibly and promptly to avoid aggressive viral replication". For more than 5-7 days, use of steroids should be restricted for those who have breathing trouble, persistent fever and increasing cough related inflammation in the airway. If, the patient's condition does not improve, the dosage should be reduced over time, and a new treatment approach should be established. While prescribing "higher doses of steroids to diabetic patients," physicians "should be careful about secondary infections". India is the world's diabetes capital. Random use of steroids for diabetes, both known and suspected, may result in superadded infections or breakthrough bacterial and fungal infections. Dexamethasone and methyl/prednisolone are the steroids utilized in COVID-19. A systemic inflammatory response in individuals with severe COVID-19 can lead to lung injury and multisystem organ failure. On the other hand, steroids' powerful anti-inflammatory properties may help to reduce negative side effects.

\subsection{Use of industrial oxygen}

There are several uses of oxygen, but industrial use of oxygen is far different from medical use. There was a massive demand for oxygen in the second wave of COVID-19; therefore, industrial oxygen was redirected to medical use. The same cylinder used in industry is diverted to health facilities and hospitals. According to WHO's guidelines, the purity and quality of industrial oxygen are far different from medical use oxygen. Industrial oxygen could be contaminated in production, storage, and distribution because there is no need for extra care for it (Anon 'Health product policy and standards', n.d.). Industrial oxygen cylinders are unsuitable for medical purposes because these cylinders are contaminated due to storage in a dusty environment, unclean cylinders and prone to micro leaks. On account of these causes, industrial cylinders may not be used for medical purposes. Industrial cylinders undergo various processes such as sealing micro leaks, deep cleaning, disinfection, and testing before medical use. Consequently, there was an acute shortage of oxygen supply in the second wave of COVID-19. Time and cost were involved in following the strict protocol to convert industrial cylinders to medical use. These strict guidelines and protocols were not followed at various levels, increasing the risk of opportunistic fungal infection (Bhatia, 2021). It happened in India because there is no law to make accountable to anyone. It is the need of time to take precautionary measures at various stages of production and distribution. Regulatory bodies of medical devices and medicines must be responsible for assuring protocols of converting the industrial cylinders to medical use for well-being. The government must give authority. Health facilities need consent from the regulatory bodies before using the industrial cylinders in medical use and must follow strict protocols. Medical staff dealing with the different instruments of oxygen supply should be trained to use instruments such as catheters, ventilators, tubings, fittings and humidifiers. They should know the process of sterilization and fumigation and assure the use of sterile water for humidification. All the mucormycosis cases should review and find out the connection between industrial oxygen and mucormycosis.

\section{Cases of mucormycosis}

Mucormycosis is caused by underlying immune system disorders such as prolonged use of steroids, diabetes, solid organ transplantation and chemotherapy (Park et al., 2011; Song et al., 2017; Lanternier et al., n.d.). Mucormycosis can also occur due to severe burns, recurrent traumas, or specific medical treatments (Blandine Rammaert et al., 2012; Bitar and Che, 2013). Mucormycosis is a fatal invasive fungal disease that occurs primarily in diabetic patients without or with other underlying disorders such as solid-organ transplantation or haematological malignancies. Rhino-orbital cerebral mucormycosis (ROCM) in immunocompromised and diabetic individuals is an uncommon but lethal fungal infection. Only a few examples of bilateral participation in ROCM have been recorded (Jiang et al., 2016; Denning and Stevens, 1990; De la Paz et al., 1992). The infection spreads from the nasal mucosa to the sinuses, orbit, and brain in ROCM, which is generally one-sided (Lam and Yuen, 2019). The primary location of mucormycosis is the ROC region, although the lack of symptoms may contribute to a postponed diagnosis. Any instance in diabetic individuals confirmed non-bacteriological sinusitis, even if there is no ketoacidosis, should raise the possibility of mucormycosis (Rammaert et al., 2012).

Five patients' medical records were analysed with ROCM between January 1995 and December 2007. Tissue biopsies were performed on all patients. It was found in histologic sections presence of nonseptate hyphae of the order mucorales. There were five patients, two women and three men ranging in age from 27 to 61 , who had diabetes. Five patients of exophthalmia, four patients with face edema, four patients with periorbital cellulitis, and cranial nerve palsy were the most common symptoms in four patients. All the patients had diabetic ketoacidosis, and a CT scan indicated that they all had rhino-orbital-cerebral involvement. Amphotericin B was administered intravenously to all the patients. Surgical debridement of necrotic tissue was performed on four individuals. Two of the patients made it out alive. The outcome of the study has shown that in diabetic individuals, mucormycosis is almost always deadly. Therefore, imaging, and histological data should be used to make an early diagnosis. This study also advised that Amphotericin B must be administered early with aggressive surgical debridement to reduce mortality (Toumi et al., 2012).

In another case report, eleven cases were analysed of ROCM with OAS (orbital apex syndrome). Mucormycosis was shown to be associated with type 2 diabetes in nine instances, a kidney transplant in one case of a traffic accident injury. Anterior rhinoscopy in all patients indicated nasal necrotic lesions or palatine; at the same time, three of them had transethmoidal optic nerve decompression. CT scan of every patient has shown rhino-orbital-cerebral involvement. Amphotericin B was administered intravenously to all the patients. Necrotic tissue was surgically debrided in nine cases. 
Three patients had been survived after the clinical management. These cases concluded that ROCM is a life-threatening illness requiring comprehensive treatment (Jiang et al., 2016).

A retrospective study evaluated the different stages of ROC mucormycosis of treatment outcomes and clinical features. This retrospective case series examined the case histories of 34 patients with a histological diagnosis of ROC mucormycosis treated between 1992 and 2000. There were three clinical phases identified, as well as three therapy groups. In the first clinical stage, patients with limited sino-nasal disease underwent sino-nasal debridement (Treatment group A). In the second clinical stage, patients with minor rhinoorbital disease underwent either sino-nasal debridement alone (Treatment group A) or orbital exenteration in addition to sino-nasal debridement (Treatment group B). Clinical stage second, patients with rhino-orbito-cerebral disease did not undergo any surgical procedure (Treatment group C). Thirty-three patients were administered amphotericin B intravenously. "Treatment success" (disease-free, stable patient with metabolic abnormality under control) and "Treatment failure" (disease-free, unstable patient with metabolic abnormality under control) were the outcomes for each group. At last, it was concluded that sinus debridement is required for rhino-orbito-cerebral mucormycosis. Early diagnosis necessitates a high level of suspicion. In individuals whose metabolic derangement is promptly controlled and orbital engagement is non-progressive, there is a clear role in retaining orbits (Nithyanandam et al., 2003).

Shatriah and his team reviewed eleven cases of ROCM in immunocompetent hosts in PubMed from 2000 to 2011. All these reviews have shown that both the genders between 16 and 59 years were equally affected. The emerging pathogen cause of ROCM is Apophysomyces elegans. In conclusion of this study, researchers said that ROCM in immunocompetent patients is forever confusing and possibly the reason for the delay at the beginning of treatment. It is necessary to warn the ophthalmologist of the evolution of this rare disease in healthy individuals (Shatriah et al., 2012). A 59-yearold immunocompetent white man was injured while cleaning an air conditioner. This injury did not respond to antibiotics and cause orbital cellulitis. Biopsy and imaging studies had shown mucormycosis. This agent was causing this case of ROCM. It is concluded that ROCM has shown orbital inflammation associated with retinal or orbital infarction and multiple cranial nerve palsies despite their immunologic status. It is suggested that early management could be done with appropriate systemic antifungal agents and appropriate surgery (Fairley et al., 2000). Effective treatment of ROCM may include; (i) prompt antifungal therapy, (ii) early diagnosis, (iii) reversal of underlying risk factors, (iv) surgical debridement where applicable (Spellberg et al., 2005). Fortis Hospital Mulund, a tertiary care center in Mumbai that was admitting COVID19 patients since the pandemic. An ICU consultant stored data electronically and looking specifically at the incidence of mucormycosis and strictly followed the protocol of steroid use, monoclonal antibodies, glycemic control and diabetes mellitus. COVID-19 patients were retrospectively assessed in this study. ICU and hospital admitted patients were analyzed in the context of mucormycosis. Maharashtra state task force and local guidelines were followed for treatment protocol. During the hospital stay and immediate outpatient department follow-up, no cases of mucormycosis were reported. Following the guidelines of the state government, low dose steroids were given to patients, which included a nurse-led strict glycemic control regime (blood glucose levels were maintained between 140 and $180 \mathrm{mg} / \mathrm{dl}$ throughout the ICU stay and were consistently achieved in 842 (82\%) patients), immunomodulatory drugs were used minimal, like monoclonal antibodies. In a tertiary care specialized COVID-19 facility, rigorous adherence to a low-dose steroid program combined with stringent glucose management managed to eliminate the danger and occurrence of mucormycosis (Mulakavalupil et al., 2021).

A lady of 62 years was admitted to ICU with a combination of emphysema, bilateral ground-glass opacities with crazy paving, and peripheral nodular consolidations on the contrast-enhanced CT. Despite being prone, the patient required veno-venous extracorporeal membrane oxygenation for rescue (ECMO). In BALF, PCR for SARS$\mathrm{CoV}-2$ and human metapneumovirus (hMPV) were also positive. Despite being prone, the patient required veno-venous extracorporeal membrane oxygenation for rescue (ECMO). In BALF, PCR for SARSCoV-2 and human metapneumovirus (hMPV) were also positive. The patient experienced significant intrapulmonary bleeding from the right main bronchus, which was stopped with cold lavages and tranexamic acid instillation. The BALF culture developed Aspergillus fumigatus and tested positive for galactomannan; therefore, therapy with intravenous voriconazole was started (Koehler et al., 2020). According to research, severely sick COVID-19 patients are more prone to have Aspergillus co-infection, which will undoubtedly raise death rates even further. A summary of mucormycosis cases and management has been shown in Table 3 .

\section{Management of mucormycosis}

Although, guidance on complicated interdisciplinary management has the potential to enhance prognosis, approaches vary by healthcare environment. In view of the European Confederation of Medical Mycology's "One World One Guideline" effort, authors from 33 countries across all United Nations regions analyzed published data on mucormycosis treatment and offered consensus guidelines that addressed regional variances. High-dose liposomal amphotericin B is suggested first-line therapy, while intravenous or delayed-release tablet posaconazole are moderately indicated and intravenous isavuconazole. The use of both triazoles as salvage therapy is strongly advised. Because of its high toxicity, amphotericin B deoxycholate is not recommended, although it may be the only alternative in resourceconstrained situations (Cornely et al., 2019). Present recommendations in haematology are confined to specific patient categories or a geographic location, or they need to be updated (Skiada et al., n.d.; Blyth et al., 2014; Cornely et al., 2014; Kung et al., n.d.; Tissot et al., n.d.). It is uncertain how long treatment for mucormycosis will take. However, if the immune defect and neutropenia are a resolved: for example, and diabetes is under control, then immunosuppression can be stopped or tapered. Therapy can be continued until signs and symptoms of infection have resolved significant radiographic improvement has occurred. Isavuconazole was given intravenously or orally for 84 days as a first-line or salvage therapy (Cornely et al., 2019; Marty et al., n.d.). Treatment duration for posaconazole oral suspension trials ranged from one week to over three years, with an average of about six months (Kim et al., 2016; Ma et al., 2015; Burik et al., n.d.; Greenberg et al., 2006; Larkin and Montero, 2003; Cornely et al., 2019). Therapeutic action and rapid diagnostic such as radiological, surgical, laboratory-based team and multidisciplinary medical consultants are required to enhance the survival rates (Vaughan et al., 2018). 
Table 3: Summary of mucormycosis cases and management

\begin{tabular}{|c|c|c|c|c|c|c|}
\hline $\begin{array}{l}\text { No. of } \\
\text { cases }\end{array}$ & $\begin{array}{l}\text { Gender } \\
\text { history }\end{array}$ & Clinical & $\begin{array}{l}\text { Site of infection/ } \\
\text { susceptibility } \\
\text { testing }\end{array}$ & $\begin{array}{l}\text { Fungus } \\
\text { species }\end{array}$ & $\begin{array}{l}\text { Management } \\
\text { drug }\end{array}$ & References \\
\hline 174 & $76 \%$ male & Major & $\begin{array}{l}\text { Rhinocerebral } \\
\text { underlying diseases } \\
\text { were diabetes } \\
(43.1 \%)\end{array}$ & Rhizopus & $\begin{array}{l}\text { Posaconazole } \\
\text { and lipid } \\
\text { amphoterincin B }\end{array}$ & (Song et al., 2017) \\
\hline 74 & $\begin{array}{l}\text { Sex ratio } \\
\mathrm{M} / \mathrm{F} 1.96\end{array}$ & $\begin{array}{l}60 \text { cases }(81 \%) \\
\text { were immuno } \\
\text { compromised }\end{array}$ & $\begin{array}{l}\text { lungs }(39.2 \%) \text {, } \\
\text { and the skin } \\
(20.3 \%)\end{array}$ & $\begin{array}{l}\text { Rhizopus genus in } \\
22 \text { cases }(29.7 \%), \\
\text { Lichtheimia } \\
\text { genus in } 19 \\
\text { cases }(25.7 \%), \\
\text { Rhizomucor } \\
\text { genus in } 14 \text { cases } \\
(18.9 \%), \text { Mucor } \\
\text { genus in } 9 \text { cases } \\
(12.2 \%), \\
\text { Cunninghamella } \\
\text { genus in one } \\
\text { case }(1.4 \%)\end{array}$ & $\begin{array}{l}\mathrm{L}-\mathrm{AmB}, \mathrm{L}-\mathrm{AmB} \\
\text { with caspofungin, } \\
\mathrm{L}-\mathrm{AmB} \text { with } \\
\text { posaconazole }\end{array}$ & (Claustre et al., 2020) \\
\hline 230 cases & $60 \%$ men & $\begin{array}{l}\text { Haematological } \\
\text { malignancies } \\
(44 \%), \text { trauma } \\
(15 \%), \\
\text { haematopoietic } \\
\text { stem cell } \\
\text { transplantation } \\
(9 \%) \text { and } \\
\text { diabetes }(9 \%)\end{array}$ & $\begin{array}{l}\text { Pulmonary }(30 \%) \text {, } \\
\text { rhinocerebral } \\
(27 \%), \text { soft tissue } \\
(26 \%) \text { and } \\
\text { disseminated } \\
\text { disease }(15 \%)\end{array}$ & $\begin{array}{l}\text { Rhizopus spp. } \\
(34 \%) \text {, Mucor spp. } \\
(19 \%) \text { and } \\
\text { Lichtheimia } \\
\text { (formerly Absidia) } \\
\text { spp. (19\%) were } \\
\text { most identified. }\end{array}$ & $\begin{array}{l}\text { Amphotericin B } \\
39 \% \text { formulations, } \\
7 \% \text { posaconazole } \\
\text { and } 21 \% \text {, received } \\
\text { both agents; } 15 \% \\
\text { of patients received } \\
\text { no antifungal } \\
\text { therapy }\end{array}$ & (Skiada et al., 2011) \\
\hline 5589 & & $\begin{array}{l}\text { Multiple } \\
\text { transplants, } \\
\text { neutropenia }\end{array}$ & $\begin{array}{l}\text { Lungs in } 191 \\
\text { patients, sinuses } \\
\text { in } 22 \text {, and other } \\
\text { sites (liver, gut, or } \\
\text { skin without } \\
\text { further organ } \\
\text { involvement) in } \\
5 . \text { Probable IA } \\
\text { involved the lungs } \\
\text { in } 106 \text { patients, } \\
\text { sinuses in } 16 \text {, } \\
\text { and other sites in } \\
2 . \text { Possible IA } \\
\text { involved the lungs } \\
\text { in } 27 \text { patients, } \\
\text { sinuses in } 5 \text {, and } \\
\text { liver in } 1\end{array}$ & $\begin{array}{l}\text { Aspergillus species } \\
(69 \%)\end{array}$ & $\begin{array}{l}\text { Amphotericin-B } \\
\text { deoxycholate or } \\
\text { lipid formulations } \\
\text { of amphotericin-B }\end{array}$ & (Marr et al., 2002) \\
\hline 1 & $\begin{array}{l}79 \text {-year-old } \\
\text { Latino male }\end{array}$ & $\begin{array}{l}\text { Diabetes mellitus } \\
\text { and hypertension }\end{array}$ & lung tissues & $\begin{array}{l}\text { Rhizopus arrhizus } \\
\text { and Aspergillus } \\
\text { fumigatus }\end{array}$ & L-AmB $400 \mathrm{mg}$ & (Johnson et al., 2021) \\
\hline 1 & $\begin{array}{l}\text { 74-year-old } \\
\text { patient }\end{array}$ & $\begin{array}{l}\text { Reflux, } \\
\text { polyarthrosis, } \\
\text { stopped smoking } \\
20 \text { years ago }\end{array}$ & Chest, pulmonary & $\begin{array}{l}\text { Aspergillus } \\
\text { fumigatus }\end{array}$ & $\begin{array}{l}\text { amphotericin } \mathrm{B} 0.5 \\
\mathrm{mg} / \mathrm{l} \text {, anidulafungin } \\
\text { and micafungin } \\
<0.016 \mathrm{mg} / \mathrm{l}, \\
\text { itraconazole } 16 \\
\mathrm{mg} / \mathrm{l} \text {, voriconazole } \\
2 \mathrm{mg} / \mathrm{l} \text { and posaco- } \\
\text { nazole } 0.5 \mathrm{mg} / \mathrm{l}\end{array}$ & (Meijer et al., 2020) \\
\hline
\end{tabular}




\begin{tabular}{|c|c|c|c|c|c|c|}
\hline 31 & & $\begin{array}{l}\text { Three patients } \\
\text { had pre-existing } \\
\text { lung diseases }\end{array}$ & Chest, pulmonary & $\begin{array}{l}\text { Aspergillus } \\
\text { fumigatus } \\
\text { in five patients }\end{array}$ & $\begin{array}{l}\text { Voriconazole and } \\
\text { anidulafungin } \\
\text { combination } \\
\text { therapy was } \\
\text { initiated in five } \\
\text { patients, and one } \\
\text { patient received } \\
\text { liposomal } \\
\text { amphotericin B }\end{array}$ & $\begin{array}{l}\text { (van Arkel et al., } \\
2020)\end{array}$ \\
\hline 1 & $\begin{array}{l}\text { 64-year } \\
\text { Female }\end{array}$ & $\begin{array}{l}\text { Lap. } \\
\text { cholecystectomy } \\
\text { for cholecystitis, } \\
\text { Arterial hyper- } \\
\text { tension, Obesity } \\
\text { with sleep apnea } \\
\text { (BMI 31.5), } \\
\text { Hyper cholester- } \\
\text { olemia, Ex- } \\
\text { smoker (30 PY; } \\
5 \text { y previously) } \\
\text { Moderate COPD } \\
\text { (GOLD 2), } \\
\text { Inhalation of } \\
\text { steroids }\end{array}$ & Azole susceptible & $\begin{array}{l}\text { Aspergillus } \\
\text { fumigatus }\end{array}$ & $\begin{array}{l}\text { Voriconazole iv } \\
\text { (6/4mg/kg BW } \\
\text { twice daily) }\end{array}$ & (Koehler et al., 2020) \\
\hline 5248 & - & $\begin{array}{l}915 \text { received } \\
\text { steroids, and } 417 \\
\text { had diabetes as } \\
\text { existing } \\
\text { co-morbidity } \\
\end{array}$ & No susceptible & $\begin{array}{l}\text { No sign of any } \\
\text { mucormycosis }\end{array}$ & $\begin{array}{l}\text { No need for any } \\
\text { antifungal drug }\end{array}$ & $\begin{array}{l}\text { (Mulakavalupil et al., } \\
\text { 2021) }\end{array}$ \\
\hline 1 & $\begin{array}{l}44 \text {-year-old } \\
\text { man }\end{array}$ & $\begin{array}{l}\text { A moderately } \\
\text { severe pneumonia } \\
\text { caused by } \\
\text { SARS-CoV-2.; } \\
\text { diabetic }\end{array}$ & $\begin{array}{l}\text { Case complained } \\
\text { of a blackish } \\
\text { discolouration } \\
\text { extending just } \\
\text { below his left eye } \\
\text { upto the left side } \\
\text { of his face to the } \\
\text { level of his mouth }\end{array}$ & Rhizopus arrhizus & $\begin{array}{l}\text { I/V liposomal } \\
\text { amphotericin-B } \\
\text { at a dose of } 5 \mathrm{mg} / \mathrm{kg} / \\
\text { day; an insulin } \\
\text { infusion was also } \\
\text { continued because } \\
\text { of persistent } \\
\text { hyperglycaemia }\end{array}$ & (Chauhan et al., 2021) \\
\hline
\end{tabular}

\section{Plants having antifungal activity}

In the last several decades, there has been a worldwide increase in the prevalence of fungal infections, as well as a growth in the resistance of specific fungus species to various fungicides used in medicine. The majority of commonly used antifungal medications have various side effects in terms of toxicity, effectiveness, and cost, and their widespread usage has resulted in the development of resistant strains (Kumar Mishra et al., 2020; Ahmad et al., 2020; Hussain et al., 2012). The area of herbal medicine has grown at an exponential rate during the last few decades. Because of its natural origins and fewer adverse effects, it has become popular in both developed and developing countries. In an experimental study, a herbal gel containing Ipomoea carnea Jacq. methanolic leaf extract was prepared and evaluated for antifungal activity. The gel might be utilized to treat cutaneous aspergillosis, face skin symptoms caused by Penicillium, cutaneous mucormycosis, and other skin diseases, according to the findings of this study (Kaushik et al., 2020; Alsayari and Wahab, 2021; Wahab et al., 2021). Many plants have been used to cure fungal infections, as described in ancient Chinese medical texts and current literature. A study was conducted to examine the antifungal activities of Traditional Chinese medicine (TCM) using consistent methods and standards. Twenty-two herbal extracts worked against Candida albicans, 52 having inhibitory effects against Cryptococcus neoformans and six against Aspergillus fumigatus. Phellodendron chinense, Syzygium aromaticum, Neopicror hizascrophulariiflora, Rosa chinensis and Curcuma longa exhibited broad-spectrum antifungal activities. Flavonoids and gallic acid were the primary antifungal components of Rosa chinensis. These compounds have shown antifungal effects that were both synergistic and additive (Jiang et al., 2020). Fifteen plants leaves extracts were examined at MIC to find the antifungal activities against the opportunistic pathogen Candida albicans isolated from oral cavity infections. The best inhibitory effects were given by the herbal extracts of Zingiber officinale, Withania somnifer, Lawsonia inermis, Cymbopogon citrates, Curcuma longa and Ganoderma lucidum, and these herbs have the potential to inhibit the growth of Candida albicans (Samadi et al., 2019; Ahmad et al., 2021). Selina-1,3,7 (11)-trien-8-one and selina-1,3,7 (11)-trien-8-one are the two components of Eugenia uniflora that exhibited antifungal activity. The performance of $E$. uniflora essential oil was considered as a fungistatic agent (dos Santos et al., 2018; Alsayari et al., 2021; Wahab et al., 2021). Many others plants have exhibited antifungal properties such as Mimosa tenuiflora, Aquilegia vulgaris, Aniba panurensis, Alibertia macrophylla, Ajania fruticulosa, Parapiptadenia rigida, Persea americana, Schinus terebinthifolius, Piptadenia colubrina, Curcuma longa and Psidium guajava. 


\section{Conclusion}

Agents of mucormycosis are different with geographical regions as in North America and Europe hematological malignancy followed by diabetes, trauma and SOT but in Mexico and India uncontrolled diabetes is the most common cause (Serris et al., 2019; Corzo-León et al., 2018). A large number of COVID-19 cases in India perhaps contributing to the present increase in mucormycosis patients. During COVID-19's second wave, the number of mucormycosis cases spiked substantially. Several additional risk aspects for mucormycosis include: neutropenia, HIV, organ transplant and malignancy. The development of mucormycosis is influenced by diabetic ketoacidosis and steroids. A rise in the cases is related to uncontrolled use of steroids and diabetes in the current scenario. Surgical debridement, antifungal drugs and early detection are the therapies to control mucormycosis. There is a need to differentiate other bacterial infections and aspergillosis from mucormycosis. In the current epidemiological conditions, clinicians should be aware of the higher likelihood of contracting this potentially deadly disease and judiciously use steroids in all patients. There is a need for data-based clinical practice. Before using the medications, there is a need to collect data on their favorable use. Many platforms designed for practical research, such as recovery and principle, have emerged to inform clinicians. Reports show that strict protocol for following steroids and tight control of glycaemia can help avoid mucormycosis. COVID-19 patients' disease severity and risk of mortality will be significantly reduced, if this fungus is identified early and further investigated. After assessing multiple cases, clinicians should be cautious that in severely COVID-19 cases, combined mucormycosis and pulmonary aspergillosis can result in secondary COVID-19 consequences. More research should be conducted on post-COVID19 mucormycosis patients in different settings to explore the risk factors further. The findings of studies must be validated in clinical trials to determine the probable role of post-COVID-19 mucormycosis.

\section{Acknowledgements}

The author declares sincere gratitude toward King Khalid University, Abha, Saudi Arabia, for their support in writing this review article.

\section{Conflict of interest}

The authors declare no conflicts of interest relevant to this article.

\section{References}

Abe, F.; Shibuya, H.; Tateyama, M.; Ommura, Y.; Azumi, N. and Kimura, K. (1986) Mucormycosis in diabetic ketoacidosis: Role of unbound iron binding capacity of transferrin'. Pathology International, 36(10):15071512.

Agrifoglio, A.; Cachafeiro, L.; Figueira, J.C.; Añón, J.M. and García de Lorenzo, A. (2020). 'Critically ill patients with COVID-19 and candidaemia: We must keep this in mind. Journal de Mycologie Medicale, 30(4): 101012

Ahmad, I.; Wahab, S.; Nisar, N.; Dera, A.A.; Alshahrani, M.Y.; Abullias, S.S. and Irfan, S. (2020). 'Evaluation of antibacterial properties of Matricaria aurea on clinical isolates of periodontitis patients with special reference to red complex bacteria'. Saudi Pharmaceutical Journal, 28(10): 1203-1209.

Ahmad, M.D.F.; Wahab, S.; Ali Ahmad, F.; Intakhab Alam, M.; Ather, H.; Siddiqua, A. and Amir Ashraf, S. (2021). A novel perspective approach to explore pros and cons of face mask in prevention the spread of SARS-CoV-2 and other pathogens. Saudi Pharmaceutical Journal, 29(2):121-133.
Ahmad, M.F.; Ahmad, F.A.; Khan, M.I.; Alsayegh, A.A.; Wahab, S.; Alam, M.I. and Ahmed, F. (2021). 'Ganoderma lucidum: A potential source to surmount viral infections through $\beta$-glucans immunomodulatory and triterpenoids antiviral properties'. International Journal of Biological Macromolecules, 187:769-779.

Ahmed,A.; Adelmann, D.; Fahal, A.; Verbrugh, H.; Van Belkum, A. and De Hoog, S. (2002). 'Environmental occurrence of Madurella mycetomatis, the major agent of human eumycetoma in Sudan'. Journal of Clinical Microbiology, 40(3):1031-1036.

Al-Obaidi, M.; Youssefi, B.; Bardwell, J.; Bouzigard, R.; Le, C.H. and Zangeneh, T.T. (2021). 'A comparative analysis of mucormycosis in immunosuppressed hosts including patients with uncontrolled diabetes in the Southwest United States'. The American Journal of Medicine, 10(1):300-317

Alanio, A.; Dellière, S.; Fodil, S.; Bretagne, S. and Mégarbane, B. (2020). 'Prevalence of putative invasive pulmonary aspergillosis in critically ill patients with COVID-19'. The Lancet Respiratory Medicine, 8(6):e48-e49.

Alfishawy, M.; Elbendary, A.; Younes, A.; Negm, A.; Hassan, W.S.; Osman, S.H. and Nassar, M. (2021). 'Diabetes mellitus and coronavirus disease (COVID19) associated mucormycosis (CAM): A wake-up call from Egypt'. Diabetes and Metabolic Syndrome: Clinical Research and Reviews, pp:102-195.

Alsayari, A.; Muhsinah, A. Bin, Almaghaslah, D.; Annadurai, S. and Wahab, S. (2021). 'Pharmacological efficacy of ginseng against respiratory tract infections'. Molecules, 26(13):40-95.

Alsayari, A. and Wahab, S. (2021). 'Genus Ziziphus for the treatment of chronic inflammatory diseases'. Saudi Journal of Biological Sciences.

Anaissie, E.; McGinnis, M. and Pfaller, M. (2009). Clinical mycology.

Annane, D. (2021). 'Corticosteroids for COVID-19'. Journal of Intensive Medicine: pp: 1-25.

Anon. According to the WHO, corticosteroids should be administered intravenously or orally to patients with severe COVID-19. Google Search'. Available at: https://www.google.co.in/search [Accessed July $11,2021]$.

Anon. 'About Mucormycosis | Mucormycosis | CDC'. Available at: https:/ /www.cdc.gov/fungal/diseases/mucormycosis/definition.html\#seven [Accessed June 14, 2021].

Anon. 'Health product policy and standards'. Available at: https:// www.who.int/teams/health-product-and-policy-standards/access-toassistive-technology-medical-devices/medical-devices/oxygen [Accessed August 3, 2021].

Anon. 'Mucormycosis Covid Symptoms, Treatment: 'Black fungus' Infection in COVID-19 patients'. Available at: https://indian express.com/article/explained/mucormycosis-in-covid-patientsfungal-infections-7308721/ [Accessed June 15, 2021].

van Arkel, A.L.E.; Rijpstra, T.A.; Belderbos, H.N.A.; van Wijngaarden, P.; Verweij, P.E. and Bentvelsen, R.G. (2020). 'COVID-19: Associated Pulmonary Aspergillosis'. American Journal of Respiratory and Critical Care Medicine, 202(1):132-135.

Artis, W.M.; Fountain, J.A.; Delcher, H.K. and Jones, H.E. (1982). 'A mechanism of susceptibility to mucormycosis in diabetic ketoacidosis: Transferrin and iron availability'. Diabetes, 31(12):1109-1114.

Auld, A.G. (1929). 'The adrenal gland'. British Medical Journal, 1(3554):322-323

Bakshi, S.S. and Kalidoss, V.K. (2021). 'COVID 19 infection and mucormycosis a dangerously increasing combination'. The Egyptian Journal of Otolaryngology, 37(1):117-129. 
Bassetti, M. and Bouza, E. (2017). 'Invasive mould infections in the ICU setting: Complexities and solutions'. Journal of Antimicrobial Chemotherapy, 72(Suppl.1):i39-i47.

Bhatia, M. (2021). 'The rise of mucormycosis in COVID-19 patients in India'. Expert Review of Anti-infective Therapy, pp:1-2.

Bitar, D. and Che, D. (2013). 'Épidémiologie des mucormycoses en France mé tropolitaine, 1997-2010'. Medecine/Sciences, 29(SPL.1):7-12.

Blot, S.; Dimopoulos, G.; Rello, J. and Vogelaers, D. (2008). 'Is Candida really a threat in the ICU?' Current Opinion in Critical Care, 14(5):600604 .

Blyth, C. and Gilroy, N. (2014). 'Consensus guidelines for the treatment of invasive mould infections in haematological malignancy and haemopoietic stem cell transplantation, 2014'. Wiley Online Library, 44(12):1333-1349.

Burik, J. and Van, Hare, R. (2006). 'Posaconazole is effective as salvage therapy in zygomycosis: A retrospective summary of 91 cases'. Academic.oup.com.

Chamilos, G.; Lewis, R.E. and Kontoyiannis, D.P. (2008). 'Delaying amphotericin B-based frontline therapy significantly increases mortality among patients with hematologic malignancy who have zygomycosis' Clinical Infectious Diseases, 47(4):503-509.

Chauhan, K.; Soni, D.; Sarkar, D.; Karuna, T.; Sharma, B.; Singh, S. and Karkhur, S. (2021). 'Mucormycosis after COVID-19 in a patient with diabetes'. The Lancet, 10(11):111-121

Chayakulkeeree, M.; Ghannoum, M.A. and Perfect, J.R. (2006). 'Zygomycosis: The re-emerging fungal infection'. European Journal of Clinical Microbiology and Infectious Diseases, 25(4):215-229.

Claustre, J.; Larcher, R.; Jouve, T.; Truche, A.S.; Nseir, S.; Cadiet, J. and Zerbib, Y. (2020). 'Mucormycosis in intensive care unit: Surgery is a major prognostic factor in patients with hematological malignancy'. Annals of Intensive Care, 10(1):74.

Cornely, O. (2014) 'ESCMID and ECMM joint clinical guidelines for the diagnosis and management of mucormycosis 2013'. Wiley Online Library, 20(S3):5-26.

Cornely, O.A.; Alastruey-Izquierdo, A.; Arenz, D.; Chen, S.C.A.; Dannaoui, E.; Hochhegger, B. and Hoenigl, M. (2019). 'Global guideline for the diagnosis and management of mucormycosis: An initiative of the European Confederation of Medical Mycology in cooperation with the Mycoses Study Group Education and Research Consortium'. The Lancet Infectious Diseases, 19(12):e405-e421.

Corzo-León, D.E.; Chora-Hernández, L.D.; Rodríguez-Zulueta,A.P. and Walsh, T.J. (2018). 'Diabetes mellitus as the major risk factor for mucormycosis in Mexico: Epidemiology, diagnosis, and outcomes of reported cases'. Medical Mycology, 56(1):29-43.

Darouiche, R.O. (2009). 'Candida in the ICU'. Clinics in Chest Medicine, 30(2):287-293.

Denning, D.W. and Stevens, D.A. (1990). 'Antifungal and surgical treatment of invasive aspergillosis: Review of 2,121 published cases'. Reviews of Infectious Diseases, 12(6):1147-1201.

Diao, B.; Wang, C.; Tan, Y.; Chen, X.; Liu, Ying, Ning, L. and Chen, L. (2020) 'Reduction and functional exhaustion of $\mathrm{T}$ cells in patients with coronavirus disease 2019 (COVID-19)'. Frontiers in Immunology, 11:827.

Fairley, C.; Sullivan, T.J.; Bartley, P.; Allworth, T. and Lewandowski, R. (2000) 'Survival after rhino-orbital-cerebral mucormycosis in an immunocompetent patient'. Ophthalmology, 107(3):555-558
Francis, J.R.; Villanueva, P.; Bryant, P. and Blyth, C.C. (2018). 'Mucormycosis in children: Review and recommendations for management'. Journal of the Pediatric Infectious Diseases Society, 7(2):159-164.

Gao, G.F. (2018). 'From “A”IV to "Z”'IKV: Attacks from Emerging and Re-emerging Pathogens'. Cell, 172(6):1157-1159.

Garcia-Vidal, C.; Moreno-García, E.; Hernández-Meneses, M.; Puerta-Alcalde, P.; Chumbita, M.; Garcia-Pouton, N. and Linares, L. (2020). 'Personalized therapy approach for hospitalized patients with COVID-19'. Clinical Infectious Diseases.

Garg, D.; Muthu, V.; Sehgal, I.S.; Ramachandran, R.; Kaur, H.; Bhalla, A. and Puri, G.D. (2021). 'Coronavirus disease (COVID-19) associated mucormycosis (CAM): Case report and systematic review of literature'. Mycopathologia, 186(2):289-298.

Giustino, G.; Pinney, S.P.; Lala, A.; Reddy, V.Y.; Johnston-Cox, H.A.; Mechanick, J.I. and Halperin, J.L. (2020). 'Coronavirus and cardiovascular disease, myocardial injury, and arrhythmia: JACC focus seminar'. Journal of the American College of Cardiology, 76(17):2011-2023.

Greenberg, R.N.; Mullane, K.; Van Burik, J.A.H.; Raad, I.; Abzug, M.J.; Anstead, G. and Herbrecht, R. (2006). 'Posaconazole as salvage therapy for zygomycosis'. Antimicrobial Agents and Chemotherapy, 50(1):126133 .

Hamdi, T.; Karthikeyan, V. and Alangaden, G.J. (2014). 'Mucormycosis in a renal transplant recipient: Case report and comprehensive review of literature'. International Journal of Nephrology, 2014.

Hirabayashi, K.E.; Idowu, O.O.; Kalin-Hajdu, E.; Oldenburg, C.E.; Brodie, F.L.; Kersten, R.C. and Vagefi, M.R. (2019). 'Invasive fungal sinusitis: Risk factors for visual acuity outcomes and mortality'. Ophthalmic Plastic and Reconstructive Surgery, 35(6):535-542.

Hussain, A.; Hussain, T. and Wahab, S. (2012). 'Phytochemical studies and antibacterial effects of Coccinia indica : Request PDF'. Lambert Academic Publishing. Available at: https://www.researchgate.net/ publication/292151143_Phytochemical_studies_and_ antibacterial_effects_of_Coccinia_indica-[Accessed October 13, 2020].

J, W.; I, B.; P, M.; W, M.; K, D.; R, and D.P.; K, L. (2012). 'Invasive pulmonary aspergillosis is a frequent complication of critically ill H1N1 patients: A retrospective study'. Intensive Care Medicine, 38(11): 1761-1768.

Jiang, B.C.; Shen, J.Y.; Wu, J.; Lu, R.Y.; Zheng, W.; Dong, J.X. and Yan, L. (2020). ‘ In vitro antifungal activity of 163 extracts from traditional Chinese medicine herbs'. European Journal of Integrative Medicine, 39: 101213

Jiang, N.; Zhao, G; Yang, S.; Lin, J.; Hu, L.; Che, C. and Wang, Q. (2016). 'A retrospective analysis of eleven cases of invasive rhino-orbitocerebral mucormycosis presented with orbital apex syndrome initially'. BMC Ophthalmology, 16(1):201-255.

John, T.M.; Jacob, C.N. and Kontoyiannis, D.P. (2021). 'When uncontrolled diabetes mellitus and severe covid-19 converge: The perfect storm for mucormycosis'. Journal of Fungi, 7(4):298.

Johnson, A.K.; Ghazarian, Z.; Cendrowski, K.D. and Persichino, J.G. (2021). 'Pulmonary aspergillosis and mucormycosis in a patient with COVID19’. Medical Mycology Case Reports, 32: 64-67.

Kaushik, K.; Sharma, R.B.; Sharma, A. and Agarwal, S. (2020). 'Formulation and evaluation of antifungal activity of gel of crude methanolic extract of leaves of ipomoea carnea jacq.' Journal of Research in Pharmacy, 24(3):368-379. 
Khan, A.A.; Khan, S.; Khan, U. and Das, K. (2020). 'The COVID-19 pandemic A scoping review'. Ann. of Phytomed., 9(1):18-26.

Kim, J.H.; Benefield, R.J. and Ditolla, K. (2016). 'Utilization of posaconazole oral suspension or delayed-released tablet salvage treatment for invasive fungal infection'. Mycoses, 59(11):726-733.

Koehler, P.; Cornely, O.A.; Böttiger, B.W.; Dusse, F.; Eichenauer, D.A.; Fuchs, F. and Hallek, M. (2020). 'COVID-19 associated pulmonary aspergillosis'. Mycoses, 63(6):528-534

Kontoyiennis, D.P.; Marr, K.A.; Park, B.J.; Alexander, B.D.; Anaissie, E.J.; Walsh, T.J. and Ito, J. (2010). 'Prospective surveillance for invasive fungal infections in hematopoietic stem cell transplant recipients, 20012006: Overview of the transplant- associated infection surveillance network (TRANSNET) database'. Clinical Infectious Diseases, 50(8): 1091-1100

KP, S.; LD, H.; RB, G.; CL, H.; PN, L.; R, H. and BT, T. (2006). 'Efficacy and safety of corticosteroids for persistent acute respiratory distress syndrome'. New England Journal of Medicine, 354(16):1671-1684.

Kubin, C.J.; McConville, T.H.; Dietz, D.; Zucker, J.; May, M.; Nelson, B. and Istorico, E. (2021). 'Characterization of bacterial and fungal infections in hospitalized patients with coronavirus disease 2019 and factors associated with health care-associated infections'. Open Forum Infectious Diseases, 8(6):1-15.

KumarMishra, K.; Deep Kaur, C.; Kumar Sahu,A.; Panik, R.; Kashyap, P.; Prasad Mishra, S. and Dutta, S. (2020). 'Medicinal Plants Having Antifungal Properties'. In Medicinal Plants: Use in Prevention and Treatment of Diseases Working Title]. Intech. Open., Reviews, 10(1):110.

Kung, H.; Huang, P. and Chen, W. (2018) Guidelines for the use of antifungal agents in patients with invasive fungal diseases in Taiwan'. Elsevier.

De la Paz, M.A.; Patrinely, J.R.; Marines, H.M. and Appling, W.D. (1992). 'Adjunctive hyperbaric oxygen in the treatment of bilateral cerebro-rhinoorbital mucormycosis'. American Journal of Ophthalmology, 114(2): 208-211.

Lam, S.C. and Yuen, H.K.L. (2019). 'Management of bilateral rhino-orbital cerebral mucormycosis'. Hong Kong Medical Journal, 25(5):408409 .

Lanternier, F. and Dannaoui, E. (2012) 'A global analysis of mucormycosis in France: the Retro Zygo Study (2005-2007)’. Academic.oup.com.

Lanternier, F, Dannaoui, E.; Morizot, G.; Elie, C.; Garcia-Hermoso, D.; Huerre, M. and Bitar, D. (2012). 'A global analysis of mucormycosis in France. Clinical Infectious Diseases, 54:112-121.

Lanternier, F. and Lortholary, O. (2009). 'Zygomycosis and diabetes mellitus' Clinical Microbiology and Infection, 15(Suppl.5):21-25.

Lanternier, Fanny, Sun, H.Y.; Ribaud, P.; Singh, N.; Kontoyiannis, D.P. and Lortholary, O. (2012). 'Mucormycosis in organ and stem cell transplant recipients'. Clinical Infectious Diseases, 54(11):1629-1636.

Larkin, J.A. and Montero, J.A. (2003). 'Efficacy and safety of amphotericin B lipid complex for zygomycosis'. Infections in Medicine, 20(4): 201-206.

Lescure, F.X.; Bouadma, L.; Nguyen, D.; Parisey, M.; Wicky, P.H.; Behillil, S. and Gaymard, A. (2020). 'Clinical and virological data of the first cases of COVID-19 in Europe: a case series'. The Lancet Infectious Diseases, 20(6):697-706.

Liu, L. (2014). 'Fields Virology, 6th Edition'. Clinical Infectious Diseases, 59(4):613-613.
Liu, M.; Spellberg, B.; Phan, Q.T.; Fu, Yue, Fu, Yong, Lee, A.S. and Edwards, J.E. (2010). 'The endothelial cell receptor GRP78 is required for mucormycosis pathogenesis in diabetic mice'. Journal of Clinical Investigation, 120(6):1914-1924.

Lv, Z.; Cheng, S.; Le, J.; Huang, J.; Feng, L.; Zhang, B. and Li, Y. (2020). 'Clinical characteristics and co-infections of 354 hospitalized patients with COVID-19 in Wuhan, China: A retrospective cohort study'. Microbes and Infection, 22(4-5):195-199.

Ma, J.; Jia, R.; Li, J.; Liu, Y.; Li, Y.; Lin, P. and Zhang, M. (2015). 'Retrospective clinical study of eighty-one cases of intracranial mucormycosis'. Journal of Global Infectious Diseases, 7(4):143-150.

Marr, K.A.; Carter, R.A.; Crippa, F.; Wald,A. and Corey, L. (2002). 'Epidemiology and outcome of mould infections in hematopoietic stem cell transplant recipients'. Clinical Infectious Diseases, 34(7):909-917.

Martínez-Herrera, E.; Julián-Castrejón, A.; Frías-De-León, M.G. and MorenoCoutiño, G. (2021). 'Rhinocerebral mucormycosis to the rise? The impact of the worldwide diabetes epidemic'. Anais Brasileiros de Dermatologia, 96(2):196-199.

Marty, F.; Ostrosky-Zeichner, L. (2016) 'Isavuconazole treatment for mucormycosis: A single-arm open-label trial and case-control analysis - The Lancet Infectious Diseases'. Elsevier. Available at: https://www.sciencedirect.com/science/article/pii/ S1473309916000712?casa_token=wqtG6aG9-nYAAAAA:0 tiMRCJG6Qa44LJiFXkB5TSCR3NmuiTbBLTbM SiXKs HG_KNSr PfBG4CbXTNZxf4yY-zbjW0kw [Accessed July 11, 2021].

Marx, R.E. and Stern, D. (2003). Inflammatory, reactive and infectious diseases. Quintessence Publishing Carol Stream, Ill, USA.

Meijer, E.F.J.; Dofferhoand, A.S.M.; Meis, J.F.; Hoiting, O. and Buil, J.B. (2020). 'Azole-resistant COVID-19-associated pulmonary aspergillosis in an immunocompetent host: A case report'. Journal of Fungi, 6(2): $1-8$.

Mishra, G.P. and Mulani, J. (2021). 'Corticosteroids for COVID-19: The search for an optimum duration of therapy'. The Lancet Respiratory Medicine, 9(1):e8.

Do Monte, E.S.; Dos Santos, M.E.L.; Ribeiro, I.B.; De Oliveira Luz, G.; Baba, E.R.; Hirsch, B.S. and Funari, M.P. (2020). 'Rare and fatal gastrointestinal mucormycosis (Zygomycosis) in a COVID-19 patient: A case report'. Clinical Endoscopy, 53(6):746-749.

Mulakavalupil, B.; Vaity, C.; Joshi, S.; Misra, A. and Pandit, R.A. (2021). 'Absence of case of mucormycosis (March 2020 - May 2021) under strict protocol driven management care in a COVID-19 specific tertiary care intensive care unit'. Diabetes and Metabolic Syndrome: Clinical Research and Reviews, 15(4):102-169.

Nithyanandam, S.; Jacob, M.S.; Battu, R.R.; Thomas, R.K.; Correa, M.A. and D'Souza, O. (2003). 'Rhino-orbito-cerebral mucormycosis. A retrospective analysis of clinical features and treatment outcomes'. Indian Journal of Ophthalmology, 51(3):231-236.

Paltauf, A. (2021). 'XXV. Mycosis mucorina'. In Archiv für pathologische Anatomie und Physiologie und für klinische Medicin Band 102. De Gruyter, pp:543-564.

Paramythiotou, E.; Frantzeskaki, F.; Flevari, A.; Armaganidis, A. and Dimopoulos, G. (2014). 'Invasive fungal infections in the icu: How to approach, how to treat'. Molecules, 19(1):1085-1119.

Park, B.J.; Pappas, P.G; Wannemuehler, K.A.; Alexander, B.D.; Anaissie, E.J.; Andes, D.R. and Baddley, J.W. (2011). 'Invasive non-aspergillus mold infections in transplant recipients, United States, 2001-2006'. Emerging Infectious Diseases, 17(10):1855-1864. 
Petrikkos, G. and Skiada, A. (2012) 'Epidemiology and clinical manifestations of mucormycosis'. Academic.oup.com.

Petrikkos, G.; Skiada, A.; Lortholary, O.; Roilides, E.; Walsh, T.J. and Kontoyiannis D.P. (2012). 'Epidemiology and clinical manifestations of mucormycosis'. Clinical Infectious Diseases, 54(Suppl.1):124.

Rammaert, B.; Lanternier, F.; Poirée, S.; Kania, R. and Lortholary, O. (2012). 'Diabetes and mucormycosis: A complex interplay'. Diabetes and Metabolism, 38(3):193-204.

Rammaert, Blandine, Lanternier, F.; Zahar, J.R.; Dannaoui, E.; Bougnoux, M.E.; Lecuit, M. and Lortholary, O. (2012). 'Healthcare-associated mucormycosis’. Clinical Infectious Diseases, 54(Suppl.1):S44-S54.

Reiss, E. (2006). 'Molecular Principles of Fungal Pathogenesis'. Emerging Infectious Diseases, 12(10):1626-1627.

Ribes, J.A.; Vanover-Sams, C.L. and Baker, D.J. (2000). Zygomycetes in human disease. Reviews, pp: 124

Roden, M.M.; Zaoutis, T.E.; Buchanan, W.L.; Knudsen, T.A.; Sarkisova, T.A.; Schaufele, R.L. and Sein, M. (2005). 'Epidemiology and outcome of zygomycosis: A review of 929 reported cases'. Clinical Infectious Diseases, 41(5):634-653

Roilides, E.; Zaoutis, T.E. and Walsh, T.J. (2009). 'Invasive zygomycosis in neonates and children'. Clinical Microbiology and Infection, 15(Suppl.5):50-54.

Russell, C.D.; Millar, J.E. and Baillie, J.K. (2020). 'Clinical evidence does no support corticosteroid treatment for 2019-nCoV lung injury'. The Lancet, 395(10223):473-475.

Samadi, F.M.; Suhail, S.; Sonam, M.; Sharma, N.; Singh, S.; Gupta, S. and Dobhal, A. (2019). 'Antifungal efficacy of herbs'. Journal of Oral Biology and Craniofacial Research, 9(1):28-32.

dos Santos, J.F.S.; Rocha, J.E.; Bezerra, C.F.; do Nascimento Silva, M.K.; de Matos, Y.M.L.S.; de Freitas, T.S. and dos Santos, A.T.L. (2018). 'Chemical composition, antifungal activity and potential antivirulence evaluation of the Eugenia uniflora essential oil against Candida spp.' Food Chemistry, 261:233-239.

Schauwvlieghe, A. and Rijnders, B. (2018). 'Invasive aspergillosis in patient admitted to the intensive care unit with severe influenza: A retrospective cohort study'. Elsevier, 6:782-792.

Serris, A.; Danion, F. and Lanternier, F. (2019). 'Disease entities in mucormycosis'. Journal of Fungi, 5(1):23.

Shang, L.; Zhao, J.; Hu, Y.; Du, R. and Cao, B. (2020). 'On the use of corticosteroids for 2019-nCoV pneumonia'. The Lancet, 395(10225):683-684.

Shatriah, I.; Mohd-Amin, N.; Tuan-Jaafar, T.N.; Khanna, R.K.; Yunus, R. and Madhavan, M. (2012). 'Rhino-orbito-cerebral mucormycosis in an immunocompetent patient: Case report and review of literature' Middle East African Journal of Ophthalmology, 19(2):258-261.

Singh, A.K.; Singh, R.; Joshi, S.R. and Misra, A. (2021). 'Mucormycosis in COVID-19: A systematic review of cases reported worldwide and in India'. Diabetes and Metabolic Syndrome: Clinical Research and Reviews, 15(4):102146.

Skiada, A.; Lanternier, F. and Groll, A. (2013). 'Diagnosis and treatment of mucormycosis in patients with hematological malignancies: Guidelines from the 3rd European Conference on Infections, pp:134.

Skiada, A.; Pagano, L.; Groll, A.; Zimmerli, S.; Dupont, B.; Lagrou, K. and LassFlorl, C. (2011). 'Zygomycosis in Europe: Analysis of 230 cases accrued by the registry of the European Confederation of Medical Mycology (ECMM) Working Group on Zygomycosis between 2005 and 2007'. Clinical Microbiology and Infection, 17(12):1859-1867.
Song, Y.; Qiao, J.; Giovanni, G.; Liu, G.; Yang, H.; Wu, J. and Chen, J. (2017). 'Mucormycosis in renal transplant recipients: Review of 174 reported cases'. BMC Infectious Diseases, 17(1):283.

Spellberg, B.; Edwards, J. and Ibrahim, A. (2005). 'Novel perspectives on mucormycosis: Pathophysiology, presentation, and management'. Clinical Microbiology Reviews, 18(3):556-569.

Tay, M.Z.; Poh, C.M.; Rénia, L.; MacAry, P.A. and Ng, L.F.P.(2020). 'The trinity of COVID-19: immunity, inflammation and intervention'. Nature Reviews Immunology, 20(6):363-374.

Tissot, F.; Agrawal, S. and Pagano, L. (2017). ECIL-6 guidelines for the treatment of invasive candidiasis, aspergillosis and mucormycosis in leukemia and hematopoietic stem cell transplant patients. Reviews, pp:301.

Toumi, A.; Larbi Ammari, F.; Loussaief, C.; Hadhri, R.; Ben Brahim, H.; Harrathi, K. and Ben Romdhane, F.; (2012). 'Rhino-orbito-cerebral mucormycosis: Five cases'. Medecine et Maladies Infectieuses, 42(12):591-598.

Vallabhaneni, S. and Mody, R.K. (2015). Gastrointestinal mucormycosis in neonates: A review. Current Fungal Infection Reports, 9(4):269274.

Vaughan, C.; Bartolo, A.; Vallabh, N. and Leong, S.C. (2018). 'A meta-analysis of survival factors in rhino-orbital-cerebral mucormycosis has anything changed in the past 20 years?' Clinical Otolaryngology, 43(6): 1454-1464.

Vellingiri, B.; Jayaramayya, K.; Iyer, M.; Narayanasamy, A.; Govindasamy, V.; Giridharan, B. and Ganesan, S. (2020). 'COVID-19: A promising cure for the global panic'. Science of the Total Environment, pp:725.

Vijayabala, G.S.; Annigeri, R.G. and Sudarshan, R. (2013). 'Mucormycosis in a diabetic ketoacidosis patient'. Asian Pacific Journal of Tropical Biomedicine, 3(10):830-833.

Villar, J.; Confalonieri, M.; Pastores, S.M. and Meduri, G.U. (2020). 'Rationale for prolonged corticosteroid treatment in the acute respiratory distress syndrome caused by coronavirus disease 2019'. Critical Care Explorations, 2(4):e0111.

Vincent, J.L.; Rello, J.; Marshall, J.; Silva, E.; Anzueto, A.; Martin, C.D. and Moreno, R. (2009). 'International study of the prevalence and outcomes of infection in intensive care units'. JAMA - Journal of the American Medical Association, 302(21):2323-2329.

Wahab, S.; Ahmad, I.; Irfan, S.; Baig, M.H.; Farouk, A.E. and Dong, J.J. (2021). 'Use of natural compounds as a potential therapeutic agent against COVID-19'. Current Pharmaceutical Design, 27(9):1144-1152.

Wahab, S.; Ahmad, I.; Irfan, S.; Siddiqua, A.; Usmani, S. and Ahmad, M.P. (2021). 'Pharmacological efficacy and safety of Glycyrrhiza glabra in the treatment of respiratory tract infections'. Mini Reviews in Medicinal Chemistry, pp:21.

Wahab, S.; Ahmad, I.; Usmani, S. and Ahmad, M.P. (2020a). 'Epidemiological Situation and Efficacy of Dexamethasone for the treatment planning of COVID-19: A perspective review'. Current Drug Delivery, pp: 17

Wahab, S.; Ahmad, I.; Usmani, S. and Ahmad, M.P. (2020b). 'Epidemiological situation and efficacy of dexamethasone for the treatment planning of COVID-19: A perspective review'. Current Drug Delivery, pp:17.

Wahab, S.; Ahmad, M.F.; Hussain, A.; Usmani, S.; Shoaib, A. and Ahmad, W. (2021). 'Effectiveness of Azithromycin as add-on therapy in COVID-19 management'. Mini-Reviews in Medicinal Chemistry, pp:21. 
Wahab, S.; Alshahrani, M.Y.; Ahmad, M.F.M.D.F. and Abbas, H. (2021). 'Current trends and future perspectives of nanomedicine for the management of colon cancer'. European Journal of Pharmacology, 910:174464.

Warrington, T.P. and Bostwick, J.M. (2006). 'Psychiatric adverse effects of corticosteroids'. Mayo Clinic Proceedings, 81(10):1361-1367.
Weiss, S.R. and Leibowitz, J.L. (2011). 'Coronavirus pathogenesis'. In Advances in Virus Research. Academic Press Inc., pp. 85-164.

Wu, Z. and McGoogan, J.M. (2020). 'Characteristics of and important lessons from the coronavirus disease 2019 (COVID-19). Outbreak in China'. JAMA, 323(13): 1239

Shadma Wahab, Khursheed Muzammil, Nazim Nasir, Atiq ul Hasan, Zeba Siddiqui, Pradeep Aggarwal and Sumbul Nasir (2021). Agents of mucormycosis outbreak associated with COVID-19. Ann. Phytomed., Volume10, Special Issue2 (COVID-19): S41-S55. http://dx.doi.org/10.54085/ap.covid19.2021.10.2.5 